\title{
Feed Restriction on Productive Performance of Layer Chickens: A Review
}

\author{
Mulugeta Walelegne $^{1^{*}} \quad$ Netsanet Beyero $^{2} \quad$ Geberemariyam Terefe $^{1}$ \\ 1 Holetta Agricultural Research Center, P.O. Box 31, Holetta, Ethiopia \\ 2 College of Agriculture and Environmental Sciences, Bahir Dar University, P.O. Box, 5501 Bahir Dar, Ethiopia
}

\begin{abstract}
Feed restriction is method of feeding where time, duration and amount of feed are limited, and it has an impact on whether a bird is capable of achieving the same productive performance as unrestricted birds. Feed restriction included of quantitative and qualitative restriction that is in quantitative to limiting the amount of feed daily given to the animals whereas a qualitative restriction is related to nutrient dilution in the diet. Different research results indicated that restriction of feed on layers production have controversial effect on feed intake, feed conversion efficiency, body weight gain, egg weight and quality. Overall, the potential of feed restriction programs as a management's tool is important to increasing the egg production, egg quality, reduce maintenance requirements and improvement of feed efficiency in layers chickens. Also can be lead to economical saving in cost of feeding in layers chicken, thus may be usefulness for commercial layers chicks production farms.
\end{abstract}

Keywords: feed restriction, Layers, performance, production

DOI: $10.7176 / \mathrm{JBAH} / 11-11-04$

Publication date: June $30^{\text {th }} 2021$

\section{INTRODUCTION}

In the poultry industry, Feed is the most expensive component. As a result, increased feed consumption has the potential to lower production costs for commercial egg producers. Several attempts have been made to limit the amount of feed consumed by layers in order to minimize feed waste and increase the use of energy and other nutrients in the egg production process. Feed restriction is one of the method used in poultry production to use feeds properly with minimum waste, and maximum utilization of nutrients for egg or meat production. Feed restriction is a form of feeding in which the amount, length, and time of feed are controlled, and it affects whether a bird can achieve the same body weight as unrestricted birds (Yu and Robinson, 1992). Feed restriction is divided into two types: quantitative and qualitative. A quantitative feed restriction denies bird's physical access to feed and water at specific times of the day, while a qualitative feed restriction denies birds maximum access to certain nutrients by providing a feed diluted primarily with inert fibres. (Giachetto et al., 2003; Leeson and summers, 2005). Feed restriction is used to slow the growth rate of fast-growing broilers, especially in alternative production systems that require long growth periods (Govaerts et al., 2000; Nielsen et al., 2003).

According to Balnave, 1984, one of the management strategies which could be employed to reduce the cost of feeding is feed restriction. Restricted feeding has been reported to improve the feed utilization efficiency in chickens. In a study done by Crounch et al. (2002) reported that quantitative feed restriction reduces the body weight and feed consumption of birds without necessarily affecting the egg production. Apart from saving the quantity of feed given to chickens, feed restriction has been reported by several researchers in reducing mortality of chickens ( Lippens et al., 2000; Tolkamp et al., 2005; Robert, 2009).

Furthermore, feed restriction in the rearing period has important effects on the laying traits, adult body weight decreases, sexual maturity age delays and mortality decreases (Bruggeman et al., 2005). Also, the number of heavy follicles decreases at the onset of laying (Hocking and Robertson, 2005). In addition, it is indicated that, in light layers genotypes, $15 \%$ feed restriction in the rearing period has positive effects on egg production traits (Ahsanul-haq et al., 1997). In contrary, other results showed that feed restriction between 6-18 weeks positively affects egg production in brown layers. Similar authors revealed that, feed restriction has a little increase in feed consumption during laying period and does not affect egg quality traits. Therefore, the objective of this review papers is to know the effect of feed restriction on productive performance of layer chickens.

\section{OVERVIEW OF FEED RESTRICTION}

In all cases, feed is the most expensive part of the process, accounting for $65-80 \%$ of the total cost of producing poultry meat and eggs (Kabir et al., 2007; Oyedeji et al., 2007). Apart from lowering rearing costs, restricting feeding during the rearing period also results in increased egg size, longer laying capacity, and lower mortality during the laying period (Robinson et al., 1978).Several approaches have been suggested for restricting nutrient intake during the rearing phase. Such methods involve alternating periods of access to feeds with periods of no access and the technique can be attributed to reduced feeding quantity on a daily basis (Robinson et al., 1978). Reports seem to disagree on the best timing of restricted feeding. According to Bruggeman et al. (1999), some researchers concluded that feed restriction should cover almost the entire of rearing and breeding period while 
others suggested that feed restriction should only be necessary during the rearing phase.

\subsection{Types of Feed Restriction}

According to Religious et al. (2001) quantitative and qualitative feed restriction are procedures that can be applied to manipulate the feeding strategies of poultry in order to decrease growth, and metabolic rate to some extent and so alleviate the incidence of some metabolic diseases as well as improving feed conversion in broilers and layers chickens.

\subsubsection{Quantitative Feed Restriction}

These methods include: physical feed restriction, limiting the level of consumption of feed in time (skip-a-day feeding) or reducing the time of illumination of feeding. Quantitative feed restriction has been observed to reduce mortality and culling (Fontana et al., 1992; Yu et al., 1992), improve feed conversion ratio (Deaton, 1995; Lee and Lesson, 2001) and allow a complete recovery of body weight if the degree of restriction was not too severe and slaughter ages were extended beyond 6 weeks (Deaton, 1995; Plavnik and Hurtwiz, 1988). Dozier et al. (2002), referred to feed restriction programs of yielding inconsistent results in the literature and that variation maybe partially attributed to differences in bird management, lighting, strain and ventilation. Also, quantitative restriction has been used for different purposes, such as reduction of broiler mortality and reduction of long bone abnormalities (Gonzales et al., 1998; Pelicano et al., 2005).

\subsubsection{Qualitative Feed Restriction}

Qualitative feed restriction is performed using diets with low energy to protein ratio (EPR); this is accomplished when dietary protein is increased or dietary energy is decreased or kept constant. As a consequence, the relative excess of protein induces higher energy utilization and, therefore, more synthesis and excretion of uric acid (Bartov, 1979). In addition, qualitative feed restriction implemented through diet dilution, and chemical methods of feed restriction and use of low protein or low energy diets (Zubair and Lesson, 1996).

\subsection{Effect of Feed Restriction on Performance of Layers 2.2.1. Feed Intake and Body Weight Change}

According to Iheukwumere et al. 2004 the average feed intake and body weight gain of the birds significantly decreased with severity of quantitative feed restriction. Similarly, Robinson et al. (1978) further indicated that irrespective of the length of the laying period, the ratio of the amount of feed $(\mathrm{kg})$ eaten to the quantity of eggs produced declined with successive increases in laying feed restriction. In addition, Tumova et al., 2002 indicated that feed intake was reduced by restrictive feeding and resulted in an improvement of feed efficiency in comparison with a control group fed ad libitum. The report also suggested that feed efficiency is not affected by feeding regimens. Etalem et al., 2009 also studied that there were no significant $(\mathrm{P}>0.05)$ differences in dry matter intake, initial body weight, final body weight as well as average daily weight gain of the birds under feed restricted and the unrestricted groups.

Moreover, Crounch et al. (2002) reported that there were differences in feed consumption during the growing phase of hens until 24 weeks of age. As birds were subjected to a phase of physical feed restriction, their feed intakes were reduced. The findings further indicated that as hens were placed back on ad libitum feeding, there was a subsequent and immediate large increase in feed consumption consistent with feeding behavior after restriction.

Tolkamp et al. (2005) indicated that restricted fed birds normally lose weight during the peak laying period because the nutrients intake of birds fails to. The results of Eitan and Soller (2001) also said that the body weight of restricted fed birds was significantly less at first egg compared to those in control. Colin et al. (1992) who suggested that feed restriction should be practiced on heavy breeds in order to avoid the excessive amount of body fat in pullets at sexual maturity and that feed restriction would result in targeted body size before birds start to lay.

\subsubsection{Growth performance and Feed Conversion Efficiency}

Hassan et al. (2003) indicated that a higher feed conversion value following feed restriction would probably mean that feed restriction retards growth, and therefore reduces feed efficiency. Plavnik and Hurtzwitz (1985) illustrated that feed restriction induces a higher efficiency of maintenance. At the age of 11 weeks Koekoek chickens are capable of consuming 3680 grams of feeds with an average feed conversion ratio (FCR) of 3.3 when given commercial feeds unrestrictedly ( Marle-Koster and Casey, 2001). During the growing period (9 to 20 weeks), birds fed unrestrictedly consumed significantly more feed than the feed restricted groups. The most restricted group consumed about 30 percent less feed than birds fed ad libitum which is a substantial saving in terms of feed cost per kilogram weight gain. Feed restriction treatment did not significantly affect the efficiency of feed utilization (Sekoni et al., 2002). The findings by similar author concluded that quantitative feed restriction did not have any significance on feed consumption and efficiency of feed for egg production. The same study of feed restriction on Japanese quail showed a non-significant difference in feed conversion efficiency among treatments during feed restriction periods (Hassan et al. 2003). 


\subsubsection{Egg Production}

The study conducted by Sekoni et al. (2002) indicated that quantitative feed restriction did not have any significant effect on hen day egg production. Feed restriction delays onset of egg production by approximately two days as compared to control (full fed) in quail production (Hassan et al., 2003). Early feed restriction does not significantly affect first egg weight and the number of eggs produced from 6 to 13 weeks of age in quail as reported by Hassan et al. (2003). In contrary, Bruggeman et al. (1999) showed that generally chickens restricted during the rearing period (7-15 weeks) had the highest average weekly egg production whereas chickens fed on ad libitum intake throughout the periods showed the lowest egg production per week. In addition, Robinson et al. (1978) also reported that it appears that the level of feed restriction imposed in the laying period is more critical than that imposed in the rearing period. Regardless of the length of the laying period, feed restriction in the rearing period consistently increased the hen-house production of laying periods.

Moreover, Feed restriction during egg production resulted in significantly higher egg production with a lower incidence of abnormal eggs. Feed restriction has significant effects on circulating levels of key metabolic hormones before the onset of egg production since pullets that are on restricted feeding for 21 weeks before being switched to ad libitum feeding exhibited dramatic changes in the levels of insulin, and glucagon's (Richards et al., 2003). Onagbesan et al., 2006 explained that restricted fed chickens slightly longer to reach peak than full-fed chickens. The ad libitum fed birds reached the maximum rate (84.5\%) of lay at 28 weeks of age and the birds under restricted feeding attained their peak egg production $(85 \%)$ at the age of 35 weeks.

\subsubsection{Egg Quality and Egg Weight}

In a study done on Rhode Island red chicken by Etalem et al. (2009) conclude that feed restriction by skip a-day feeding system at 35, 42,49 and 56 days of age resulted in higher egg weight and can be considered as the optimum age for pullet rearing. Additionally, feed restriction at 63, 70,77 and 84 days of age could also be recommended due to heavier uterus weight and longer length in absolute term as these attributes indicate good consistency for the subsequent egg production. Crounch et al. (2002) showed that for the entire lay period, cracked and soft-shelled egg production percentage was greater for the birds that were fed restricted from 3 to 16 weeks of age. There was also no effect of feed restriction treatment on percentage of double yolked and large egg production. Similar author also illustrated that Percentage of eggs cracked in the incubator was also significantly higher from hens that were under restricted feeding during the rearing period compared to hens subjected to other regimes (ad libitum feeding from 3 to 24 weeks; ad libitum feeding from 16 to 24 weeks and feed restriction from 3 to 24 weeks) (Crounch et al., 2002). Robinson et al. (1978) indicated that ad libitum fed birds can have as many as 12 to 15 large yellow follicles. A high proportion of those follicles are destined to become double yolked eggs. Sometimes two ovulations may occur in a single day, but both eggs have poor shell quality. Miles and Jacqueline (2000) showed that a feed restriction programme would result in a slight decrease in egg size that is of less consequence once the majority of the eggs are in the large category.

According to Robinson et al. (1978) significantly larger number of eggs heavier than 60 grams and significantly fewer eggs lighter than 45 grams were produced in each period by the birds that had been restricted during rearing than those that had not. On the other hand, restrictive feeding in the laying period depressed egg size. According to Renema et al. (1999), the early sexual maturity of ad libitum fed chickens compared to restricted fed ones throughout rearing is believed to be nullified by production of small eggs early in the laying period. The report by Robinson et al. (1978) further indicated that the proportion of cracked eggs tended to decrease with increasing severity of feed intake restriction in the laying period. Specific gravity of eggs was also markedly increased by feed intake restriction in the rearing period and tended to increase with increasing severity in the laying period. Feeding level contributed substantially to egg size (Renema et al., 2007).

\section{CONCLUSION}

In general, the potential of feed restriction programs as a management's tool is important to increasing the egg production, egg quality, reduce maintenance requirements and improvement of feed use efficiency in layers chickens' production. Also can be lead to economical saving in cost of feeding in layers chicken production, thus may be usefulness for commercial layers chicks production farms.

\section{Reference}

Ahsan-ul-haq, N. Ahmad S.Rasool and T.H. Shah, 1997. Effect of light and feed restriction during rearing on production performance of egg strain layers .Asian Aust.J.Anim.Sci. 10:657-664.

Bartov, I., 1979, November. Nutritional factors affecting quantity and quality of carcass fat in chickens. In Federation Proceedings (Vol. 38, No. 12, pp. 2627-2630).

Balnave D, 1984. The influence of body weight at pointof- lay on the production responses of Restrictedreared Pullets. Aust J Agric, 35: 845-849.

Bruggeman, V., E. D’hondt, L. Berghmen, N. Buys, M. Safi, O. Onagbesan, D.Vanmontfort, F. Vandesande and E. Decuypere. 1999. Effects of timing and duration of feed restriction during rearing on reproductive 
characteristics in broiler breeder females. Poultry Science 78:1424-1434

Bruggeman, V., O. Onagbesan, M.O.Ragot, S. Metayer and S. Cassy et al., 2005. Feed allowance-genotype interaction in broiler breeder hens.Poult.Sci. 84:298-306.

Crounch, AN, JL Grimes, VL Christensen and KK Krueger, 2002. Effect of physical feed restriction during rearing on large white turkey breeder hens. 1. Growth performance. Poult Sci, 81: 9-15.

Deaton, J.W., 1995. The effect of early feed restriction on broiler performance. Poultry Science, 74(8), pp.12801286.

Eitan Y and M Soller, 2001. Effect of photoperiod and quantitative feed restriction in a broiler strain on onset of lay in females and onset of semen production in males: A genetic hypothesis. Jerusalem: Israel.Poult Sci, 82: 1163-1169.

Etalem T., Berhan T., Aynalem H., and Tadelle D., 2009. Effects of feed restriction on production and reproductive performance of Rhode Island Red pullets. Afr J Agric Res, 4: 642-648.

Fontana, E.A., Weaver Jr, W.D., Watkins, B.A. and Denbow, D.M., 1992. Effect of early feed restriction on growth, feed conversion, and mortality in broiler chickens. Poultry science, 71(8), pp.1296-1305.

Giachetto, P.F., Guerreiro, E.N., Ferro, J.A., Ferro, M.I.T., Furlan, R.L. and Macari M., 2003. Performance and hormonal profile in broiler chickens fed with different energy levels during post restriction period. Animal Nutrition, 38: 6-12.

Govaerts, T., Room, G., Buyse, J., Lippens, M., De Groote, G. and Decuypere, E., 2000. Early and temporary quantitative food restriction of broiler chickens. 2. Effects on allometric growth and growth hormone secretion. British Poultry Science, 41 (3): 355-362.

Hassan, S. M.., M. E. Mady, A. L. Cartwright, H. M. Sabri, and M. S. Mobarak. 2003. Effect of early feed restriction on reproductive performance inJapanese Quail (Coturnix coturnix japonica). Poultry Science 82:1163-1169.

Hocking, P.M. and G.W. Robertson, 2005. Limited effect of intense genetic selection for broiler traits ovarian function and follicular sensitivity in broiler breeders at the onset of lay. Brit.Poult.Sci, 46:354-360.

Leeson S. and Summers J.D., 2005. Feeding programs for broiler chickens: growth restriction. Commercial Poultry Nutrition, 3rd Edition, University Books, Guelph, Ontario; page 248-251.

Lippens M, G Room, De Groote and E Decuypere, 2000. Early and temporary quantitative food restriction of broiler chickens. Effects on performance characteristics, mortality and meat quality. Br Poult Sci, 41: 343354.

Miles R.D and P.J. Jacgueline. 2000. Fact sheet.PS049. Department of Dairy and Poultry Science. Florida cooperative extension service. University of Florida.

Nielsen, B.L., Litherland,M. and Noddegaard, F., 2003. Effects of qualitative and quantitative feed restriction on the activity of broiler chickens. Applied Animal Behaviour Science, 83:309-323.

Onagbesan, O.M., S. Metayer, K. Tona, J. Williams, E. Decuypere and V. Bruggeman. 2006. Effects of genotype and feed allowance on plasma luteinizing hormones, Follicle Stimulating hormones, progesterone's, estradiol levels, follicle differentiation, and egg production rates of broiler breeder hens. Poultry Science 85:1245-1258.

Oyedeji, J.O., A.M. Orheruata and M. Omatsuli. 2007. Effects of feed rationing on the laying performance of 40 weeks in lay hens. Journal of Food, Agriculture and Environment 5: 301-303.

Tolkamp B, JV Sandilands and I Kyriazakis, 2005. Effects of qualitative feed restriction during rearing on the performance of broiler breeders during rearing and Lay. Edinburgh EH9 3JG, United Kingdom.

Renema, R.A., F.E, Robinson. J.A, Proudman, M, Newcombe, R.A, Mckay. 1999. Effect of body weight and feed allocation during sexual maturation in broiler breeder. 2. Ovarian morphology plasma hormone profiles. Poultry Science 78:629-639.

Renema, R.A., F.E. Robinson, and M.J. Zuidhof. 2007. Reproductive efficiency and metabolism of female broiler breeders as affected by genotype, feed allocation, and age at photo stimulation. 2. Sexual maturation. Poultry Science 86: 2267-2277.

Religious, K.B., Tesseraud, S., Piccady, O.A. (2001) Food neonatale and early development of table fowl. INRA. Production. Animal, 14, 219-230.

Richards, M.P., S.M. Poch, C.N. Coon, R.W. Rosebrough, C.M. Ashwell and J.P. Mc Murtry. 2003. Feed restriction significantly alters lipogenic gene expression in broiler breeder chickens. Journal of Nutrition $1: 707-715$

Robert C, 2009. Effect of Early Feed Restriction on Growth in Broiler Chickens. Roman: Oradea.

Robinson, D., G. Horsnell and P.J. McMahon. 1978. Restricted feeding of egg strain chickens during growth and throughout an extended laying period. Australian Journal of Experimental Agriculture and Animal Husbandry. 18:658-666

Sekoni, A.A. I. A. Adeyinke and S. O. Ogundipe. 2002. The effect of quantitative feed restriction on pullet development and subsequent egg production. Tropical Journal of Animal Science 5 :(2) 19-28.

Yu, M.E.; Robinson, F.E.; Clandinin, M.T.; and Bodnar, L., (1990). Growth and body composition of broiler 
chickens in response to different regimes of feed restriction. Poult. Sci., 69:2074-2081.

Yu, M.W. and Robinson, F.E., 1992. The application of short-term feed restriction to broiler chicken production: a review. Journal of Applied Poultry Research, 1(1), pp.147-153. 